\title{
A TEORIA DO RECONHECIMENTO NO DOCUMENTÁRIO ÔNIBUS 174
}

\author{
The recognition theory in documentary bus 174
}

La teoría del reconocimiento en documental bus 174

Lorena Cruz Esteves Mestre em Comunicação pela Universidade Federal do Pará estevesjornalismo@gmail.com

Luciana Miranda Costa Professora da Universidade Federal do Rio Grande do Norte e da Universidade Federal do Pará lmirandaeua@gmail.com

Monique Feio Igreja Professora da Universidade Federal do Pará moniredacao@gmail.com

\section{Resumo}

Este artigo propõe uma análise do documentário brasileiro Ônibus 174, dirigido por José Padilha, com base na Teoria do Reconhecimento do filósofo alemão Axel Honneth. $\mathrm{O}$ objetivo é fazer uma correlação entre os três âmbitos do reconhecimento: amor, direito e solidariedade, tidos como essenciais para garantir a realização plena do indivíduo em sociedade, com elementos da trajetória de vida de Sandro do Nascimento, o sequestrador do ônibus. Da mesma maneira, com base na observação do documentário, pretende-se refletir sobre como, conscientemente, Sandro utilizou a mídia como espaço de reconhecimento e de que forma o reconhecimento pode ser identificado também na decisão de José Padilha na escolha do gênero.

Palavras-chave: Documentário. Ônibus 174. Mídia.

\begin{abstract}
This article proposes an analysis of Bus 174 a Brazilian documentary. It was directed by José Padilha, and it was based on recognition theory of the German philosopher Axel Honneth. Its goal is to make a correlation between three levels of recognition: love, law and solidarity, once they are considered essential to ensure the full realization of individuals in society. This documentary also shows Sandro do Nascimento's life journey, the bus hijacker. Similarly, being based on the documentary observation, this article intends to reflect on how Sandro used media, consciously, as a recognition space. Moreover it shows how recognition is identified in José Padilha's genre choice.
\end{abstract}

Key words: Documentary. Bus 174. Media. 


\section{Resumen}

Este artículo propone un análisis del documental brasileño autobús 174, dirigida por José Padilha, basado en la teoría del reconocimiento del filósofo alemán Axel Honneth. El objetivo es hacer una correlación entre los tres niveles de reconocimiento: el amor, la ley y la solidaridad, que se consideran esenciales para garantizar la plena realización de la persona en la sociedad, con elementos de la trayectoria de vida de Sandro do Nascimento, el secuestrador de autobús. Del mismo modo, a partir de la observación del documental se pretende reflexionar sobre cómo conscientemente Sandro utilizó los medios de comunicación en el reconocimiento del espacio y cómo el reconocimiento también se puede identificar en la decisión de José Padilha en la elección del género.

Palabras clave: Documental. Bus 174. Medio.

\section{INTRODUÇÃO}

O documentário brasileiro Ônibus 174, dirigido por José Padilha, retrata o sequestro que marcou o dia 12 de junho de 2000, quando Sandro do Nascimento tomou os passageiros de ônibus da linha 174, no Rio de Janeiro, como reféns. O caso teve transmissão ao vivo por 4 horas ininterruptas, paralisando o país em frente à televisão, com uma "plateia" estimada em 54 milhões de espectadores.

Lançado em 22 de outubro de 2002, o documentário foi baseado em uma investigação cuidadosa de imagens de arquivo, entrevistas e documentos oficiais, visando retratar a história de vida de Sandro e os fatores que levam milhares de meninos em situação de risco a virarem moradores de rua e entrarem no mundo da criminalidade.

Abordando diversos aspectos, com um olhar psicológico, sociológico e comunicacional, Padilha convida o telespectador a refletir sobre a questão da violência, exclusão social e invisibilidade. E no intuito de propor uma nova reflexão sobre o fato, o presente artigo traz à luz a Teoria do Reconhecimento para embasar a análise do documentário.

\section{A TEORIA DO RECONHECIMENTO DE AXEL HONNETH}

As lutas sociais e suas implicações têm recebido diversas contribuições teóricas e a ideia de reconhecimento tem se firmado como essencial para compreender a dimensão moral dos conflitos sociais e sua complexidade. Ela fornece elementos para que a relação entre indivíduo e comunidade seja descortinada, a partir das variadas formas de sociabilidade decorrentes da luta por reconhecimento. A Teoria do Reconhecimento Intersubjetivo e Social, 
desenvolvida pelo filósofo alemão Axel Honneth ${ }^{1}$, destaca a "gramática moral" que rege os conflitos sociais. Embasada nos estudos sobre formação de identidade de George Mead (1863-1931) e nas premissas universais de reconhecimento social de Georg Hegel (17701831), a teoria de Honneth se pauta na ideia hegeliana de que a origem dos conflitos sociais está relacionada à luta por respeito e reconhecimento intersubjetivo, como também no pensamento de Mead, quando afirma que a identidade dos sujeitos está atrelada à experiência do reconhecimento intersubjetivo. Entretanto, de acordo com Honneth, as proposições de Mead e Hegel não conseguiram esclarecer as formas de desrespeito que, a partir do não reconhecimento, motivam os conflitos sociais (FUHRMANN, 2013).

Conforme Mendonça (2009, p.145), o modelo teórico de Honneth procura ultrapassar a ideia de que as lutas travadas no contexto social são geradas simplesmente pela razão instrumental e pelo desejo de autoconservação: "Para Honneth, é por meio do reconhecimento intersubjetivo que os sujeitos podem garantir a plena realização de suas capacidades e uma auto-relação [sic] íntegra, uma vez que as identidades são construídas relacionalmente". O filósofo defende que o reconhecimento é construído em três dimensões: do amor, do direito e da solidariedade. Dessa forma, segundo Fuhrmann (2013), no momento em que Honneth atribui a origem dos conflitos sociais à ausência do reconhecimento subjetivo e social, posiciona-se contra a ideia das teses que relacionam a precariedade econômica como fator principal da violência e desajustes sociais.

Ao detalhar a dimensão do amor, o filósofo alemão enfatiza que uma relação emotiva forte, desenvolvida na infância, é essencial para que o indivíduo adquira autoconfiança. À esfera do direito, caberia a dignidade, promotora do autorrespeito, pois permite que os sujeitos sejam tratados com igualdade, enquanto que a terceira dimensão, a da solidariedade, refere-se ao aspecto social, à valorização do sujeito no grupo familiar e institucional que está inserido, que o faz desenvolver a autoestima necessária para conviver em sociedade (FUHRMANN, 2013).

A partir da análise da história de vida de Sandro do Nascimento, retratada no documentário 2 Ônibus 174, é possível constatar que o diretor José Padilha enfoca na narrativa os três âmbitos de reconhecimento defendidos por Axel Honneth. A negação das formas de reconhecimento, detalhadas acima, foi decisiva para que Sandro não se realizasse de forma

\footnotetext{
${ }^{1}$ Axel Honneth é o atual representante da tradição da teoria crítica da Escola de Frankfurt.

${ }^{2}$ De acordo com Nichols (2005), o gênero documental tem a capacidade de enfocar questões que necessitam de atenção. O autor elucida que o documentário possibilita visões que "colocam diante de nós questões sociais e atualidades, problemas recorrentes e questões possíveis. O vínculo entre o documentário e o mundo histórico é forte e profundo. O documentário acrescenta uma nova dimensão à memória popular e à história social” (NICHOLS, 2005, p. 27).
} 
sadia tanto social, quanto individualmente, e assim demonstrasse o reconhecimento recusado por meio de um comportamento violento. Levando em consideração esse fato, a seguir serão explanadas as três dimensões que compõem o reconhecimento e suas respectivas relações com os fatos que marcaram a trajetória pessoal de Sandro.

\subsection{Dimensão do Amor}

O reconhecimento do amor é fundamental no processo de socialização do indivíduo. Valendo-se dos trabalhos desenvolvidos por Winnicott sobre os estágios primitivos do desenvolvimento emocional do ser humano, Honneth defende que é na relação entre mãe e bebê, durante a fase inicial do desenvolvimento infantil, que se dá o primeiro nível de reconhecimento. A total dependência do bebê e a prontidão da mãe para atender suas necessidades fazem com que não haja individualidade entre eles e que se sintam parte de um único ser. Ao voltar às atividades diárias, a mãe passa a não poder atender de imediato as necessidades do bebê, o que acarreta na dissolução desse laço simbiótico mantido até então e estimula que a criança amadureça (SAAVEDRA; SOBOTTKA, 2008).

Esta fase de desenvolvimento, denominada por Winnicott como de "relativa independência", é composta por dois mecanismos trabalhados pela criança, elencados por Honneth como "destruição" e "fenômeno de transição". O primeiro está relacionado à fase que o bebê reconhece a mãe como ser independente e dotado de desejos próprios, o que acarreta em atitudes agressivas por parte da criança, caracterizando um tipo de luta, fato que demanda o entendimento da mãe. "A partir dessa experiência de reconhecimento recíproco os dois começam a vivenciar também uma experiência de amor recíproco sem regredir a um estado simbiótico" (HONNETH, 2003, apud SAAVEDRA; SOBOTTKA, 2008, p.10).

Entretanto, segundo os autores, a criança apenas conseguirá passar pelo fenômeno de transição se tiver obtido confiança na dedicação em seu relacionamento maternal. Nesse sentido, Saavedra e Sobottka (2008) enfatizam a importância de uma relação bem consolidada entre criança e mãe, nutrida com confiança e cuidado, para o estabelecimento saudável da personalidade do indivíduo, desenvolvendo o que Honneth chama de "autoconfiança".

Esse desenvolvimento primário da capacidade de autoconfiança é visto por Honneth (2003, p.168) como a base das relações sociais entre adultos. Honneth vai além e sustenta que o nível de reconhecimento do amor é o núcleo fundamental de toda a moralidade (p. 172). Portanto, este tipo de reconhecimento é responsável não só pelo desenvolvimento do auto-respeito [sic] (Selbstachtung), mas também pela base de autonomia necessária para a 
participação na vida pública (p. 174) (SAAVEDRA; SOBOTTKA, 2008, p.11).

Dessa forma, é possível constatar que o rompimento abrupto do vínculo entre mãe e filho pode acarretar graves consequências mentais e emocionais ao indivíduo. A partir de relatos inseridos no documentário Ônibus 174, somos remontados a um fato que marcou a trajetória de vida de Sandro: o assassinato da mãe na sua frente quando ele tinha apenas seis anos de idade. A narração de uma reportagem publicada no dia 27 de março de 1988 no jornal O Fluminense e o relato de Julieta do Nascimento, tia de Sandro, detalham as circunstâncias da morte - "Do balcão até o lado de fora havia um rastro de sangue, deixado pela vítima, caindo entre a porta até a calçada, onde se arrastou para o lado de fora, gritando por socorro sem que ninguém a atendesse" (PADILHA, 2002).

Clarice Rosa do Nascimento, mãe de Sandro, era comerciante no bairro de Boa Vista, Rio de Janeiro, e estava grávida de cinco meses. De acordo com a reportagem, era uma pessoa alegre, bem humorada, comunicativa e adorada por seus fregueses e pelas crianças. A tragédia abalou os moradores do bairro e afetou profundamente a vida de Sandro.

Fecho o olho e vejo como foi a cena de Sandro ter visto aquelas três pessoas agredindo a mãe dele, esfaqueando a mãe dele, e eu tenho a impressão que ele ficou com a mãe dele sofrendo, com a faca nas costas, entendeu? Ele viu a faca nas costas da minha irmã, tenho certeza que ele viu (PADILHA, 2002).

Sem pai, nem avós, Sandro ficou sem ninguém que o amparasse. É nesse momento que sai de casa e passa a viver nas ruas, envolvendo-se com crianças em situação de vulnerabilidade. No documentário Ônibus 174, um dos meninos que dividiu as ruas com Sandro expõe a falta da dimensão afetiva de sua trajetória: "O Mancha ${ }^{3}$ veio pra rua criança, cara, então ele não teve tempo pra ter o amor de ninguém, entendeu? Então, a única coisa que ele aprendeu na rua foi sobreviver, mano" (PADILHA, 2002).

Com a perda da mãe, enquanto Sandro ainda estava na fase de desenvolvimento infantil, houve o impacto no reconhecimento do amor, o primeiro e fundamental nível de reconhecimento segundo Honneth, fator decisivo para que Sandro desenvolvesse uma relação negativa com ele próprio, extinguindo sua autoconfiança, culminando também na dificuldade

\footnotetext{
${ }^{3} \mathrm{O}$ apelido "Mancha" foi atribuído a Sandro quando se envolveu com meninos que viviam nas ruas, devido a uma mancha que tinha no corpo.
} 
em tecer relações sociais solidificadas e na falta de autonomia para que se inserisse na vida pública.

A forma mais básica do não reconhecimento é a negação de afeto e de respeito. A consequência é a insegurança emocional e física, uma fratura na autoconfiança que se constitui na premissa psíquica para o desenvolvimento de todas as demais formas de autoestima (FUHRMANN, 2013, p. 179).

\subsection{Esfera do Direito}

De acordo com Saavedra e Sobottka (2008, p.11), a segunda dimensão do reconhecimento é guiada por duas perguntas: "Qual é o tipo de auto-relação [sic] que caracteriza a forma de reconhecimento do direto?" e "como é possível que uma pessoa desenvolva a consciência de ser sujeito de direito?" A partir desse direcionamento, Honneth se propõe a abordar como surgiu o direito moderno e de que forma, por meio de seu fenômeno histórico, é possível encontrar uma nova forma de reconhecimento. Assim, o filósofo alemão relaciona a esfera do direito ao conceito de status.

Honneth pretende, portanto, demonstrar que o tipo de reconhecimento característico das sociedades tradicionais é aquele ancorado na concepção de status: em sociedades desse tipo, um sujeito só consegue obter reconhecimento jurídico quando ele é reconhecido como membro ativo da comunidade e apenas em função da posição que ele ocupa nesta sociedade (SAAVEDRA; SOBOTTKA, 2008, p.11).

Com a transição para a modernidade, há uma mudança na base da estrutura social e assim uma modificação nas relações de reconhecimento - os privilégios atribuídos a determinadas pessoas da sociedade passam a não ser mais aceitos pelo sistema jurídico, que determina que o direito deve contemplar de forma igual todos os indivíduos. Essa nova forma de reconhecimento jurídico da era moderna é abordada por Honneth, que mostra ter surgido junto a ela uma separação da função entre o direito e o juízo de valor. (HONNETH, 2003, apud SAAVEDRA; SOBOTTKA, 2008, p.11). Na visão do filósofo alemão, os agentes sociais apenas desenvolvem a concepção de que são sujeitos de direito quando em seu processo histórico surge uma forma de proteção jurídica, que garante a sua participação na formação pública da vontade, como também lhes confere bens materiais suficientes para que sobrevivam. 
Dessa forma, para Honneth, o âmbito do reconhecimento vai além das capacidades inerentes ao sentido moral do sujeito de direito, perpassando as condições necessárias para que o sujeito viva com dignidade e possibilitando que o mesmo desenvolva o autorrespeito. Saavedra e Sobottka (2008) refletem que a violação desse tipo de respeito tem como consequência o sentimento individual de injustiça, afetando o componente da personalidade relacionado à integridade pessoal.

A exclusão e humilhação sociais geradas pela falta de garantia dos direitos básicos do indivíduo promovem as desigualdades vivenciadas no contexto social. $\mathrm{O}$ enfoque dado à vida de Sandro do Nascimento pelo diretor José Padilha no documentário Ônibus 174, possibilita que direcionemos o olhar para as diversas feridas latentes da sociedade, que são geradoras dos muitos Sandros existentes. A dignidade, essencial para a garantia do autorrespeito, foi desde cedo tolhida da vida de Sandro.

Aos seis anos de idade, após o assassinato da mãe, Sandro passa a ter a rua como moradia. As diferenças sociais e humilhações presentes na realidade dos que vivem nas ruas são apresentadas logo no início do documentário, em depoimentos como o de Luciana, moradora de rua há 19 anos. A voz de Luciana ecoa enquanto imagens panorâmicas da cidade do Rio de Janeiro expõem as diferenças sociais marcadas no urbano.

É um chão gelado, não tem um conforto [...] o playboyzinho deitado lá em cima, em cima de uma cama, a gente deitado aqui embaixo no chão. Amanhã de manhã levanta, às vezes não tem um café pra tomar e a gente vai pra porta da padaria pedir um café, às vezes mermo roubar porque não tem o que comer. Quando cresce, já cresce revoltado (PADILHA, 2002).

Por meio da fala acima, é possível constatar a ausência de igualdade e reconhecimento que deviam compor a esfera do direito, que, segundo Fuhrmann (2013, p.179) “deve assegurar ao homem/mulher uma ampliação das suas liberdades individuais, independente da classe social a que pertença, arrefecendo as desigualdades e promovendo o autorrespeito". A mínima dignidade, conquistada tendo um lugar para dormir e um alimento para consumir, é aviltada daqueles que passam pelo processo de "rualização", fator que gera o sentimento de injustiça e revolta, evidenciado na fala de Luciana, e, muitas vezes, ocasiona situações de conflito, como a que culminou no sequestro do ônibus 174 .

Como se não bastassem os traumas psicológicos e emocionais decorrentes da vida nas ruas, Sandro viveu um episódio que colaborou como fio condutor para o crime no ônibus 174 , 
a chamada chacina da Candelária ${ }^{4}$. O fato é apresentado no documentário com a reprodução do momento em que Sandro, com uma das vítimas sob a mira do revólver, fala com os policiais: "Aqui o bagulho é sério, meu irmão. [...] Não mataram os irmãozinho da Candelária? Eu tava lá!” (PADILHA, 2002). Sandro viu os amigos morrerem na chacina e deixa claro que o episódio da Candelária ainda estava vivo em sua memória.

\begin{abstract}
Nós não tínhamos resolvido a tragédia da candelária e já estávamos vivendo uma outra tragédia que era, em certo sentido, uma extensão daquela primeira. Sandro que é vítima da Candelária, agora se converte no algoz do novo drama, quase que pra nos acordar pro fato de que nós precisamos resolver essa questão que é maior, é maior que a candelária, é maior que o 174, que vigário geral, todas as nossas tragédias cotidianas (PADILHA, 2002).
\end{abstract}

O sentimento de injustiça social pode apontar um problema, mas não sua solução. "Honneth entende que é necessária a articulação política de um movimento social para que o sentimento de injustiça do indivíduo passe a ter relevância política" (SAAVEDRA E SOBOTTKA, 2008, p.16). Nesse sentido, é possível afirmar que o sentimento de injustiça de Sandro e da parcela excluída da sociedade não é considerado pelo Estado, que, pelo contrário, posiciona-se omisso frente às consequências dos desajustes sociais e nega direitos garantidos aos cidadãos na Constituição Brasileira de 1988, tais como educação, saúde, trabalho, moradia, lazer e proteção à infância.

Na medida em que Sandro não é possibilitado de ter o pleno exercício de sua cidadania, sua participação na sociedade passa a ser constituída pela invisibilidade. A consequência de uma vida marcada pela exclusão social foi evidenciada por Sandro quando sequestra o ônibus e mantêm reféns. No dizer de Saavedra e Sobottka (2008, p.15): "As reações provocadas pelo sentimento de injustiça devem ser vistas como o estopim par excellence da luta por reconhecimento". A ausência da forma de reconhecimento pertencente à esfera da solidariedade também pode ser apontada como fator para a revolta e consequente violência praticada por Sandro.

\title{
2.3 A dimensão da solidariedade
}

\footnotetext{
${ }^{4}$ A chacina da Candelária foi uma das maiores tragédias da história recente do Brasil. Ocorreu na noite do dia 23 de julho de 1993, quando sete crianças em vulnerabilidade social foram mortas por policiais militares enquanto dormiam em uma praça localizada em frente à igreja da Candelária, no Rio de Janeiro. De acordo com o documentário Ônibus 174, 62 crianças sobreviveram ao episódio.
} 
Segundo Saavedra e Sobottka (2008), o reconhecimento visto a partir da solidariedade é entendido por Honneth (2003) como um tipo normativo que corresponde às variadas maneiras de autorrelação valorativa. O filósofo enfatiza que, com a passagem da sociedade tradicional para a moderna, vem à tona uma forma de individualização nas relações. Apesar desse fato, estariam no âmbito da integração social os valores e objetivos que servem como referência para que a moralidade pessoal do indivíduo seja avaliada, alcançando assim a autocompreensão social. Dessa forma, na concepção de Honneth, uma pessoa apenas se sente valorizada quando suas capacidades individuais são reconhecidas, estabelecendo uma tensão, pois na sociedade moderna o indivíduo busca formas de se autorrealizar, como também procura ser integrante de um sistema de avaliação social. Assim, a solidariedade estaria vinculada à estima entre indivíduos, gerada por relações sociais com simetria, que possibilitam o desenvolvimento da autorrealização do indivíduo (SAAVEDRA; SOBOTTKA, 2008).

A partir do momento em que o modo de vida de um agente social não é aprovado e valorizado no contexto familiar e social, o sujeito não desenvolve a autoestima necessária para conviver em sociedade (FUHRMANN, 2013). No documentário Ônibus 174 fica evidente que o desprezo e a humilhação foram sentimentos recorrentes na vida de Sandro do Nascimento. Uma série de fatores contribuiu para que sua estima social fosse renegada, como o fato de ser analfabeto e nunca ter trabalhado, aspectos salientados na fala de Sandro, quando, após ter fugido da cadeia, procura a assistente social identificada como Yvone para pedir emprego, dois meses antes do episódio do ônibus 174.

Ele disse pra mim: Olha, tia Yvone, eu tô cansado dessa vida, eu não aguento mais, eu queria trabalhar, mas quem é que vai me dar um emprego? A senhora olha pra mim e vê se alguém vai me dar um emprego, eu não sei ler nem escrever, eu não tenho carteira de trabalho, eu nunca trabalhei. Eu vou fazer o que da minha vida a não ser isso que eu faço? Quem é que vai me dar uma chance? Ninguém, ninguém nunca deu (PADILHA, 2002).

Para Honneth, a experiência de menosprezo, vivenciado pela falta de reconhecimento da esfera da solidariedade, é um dos principais motivos para a deflagração dos conflitos sociais (HONNETH, 2009, apud FUHRMANN, 2013). A autoestima, sem a qual não é possível se realizar socialmente, segundo Honneth, foi recuperada por Sandro no momento que realiza o sequestro do ônibus. É nesse pequeno momento de glória que ele consegue 
despertar um sentimento social, mesmo que negativo, para que sua existência seja reafirmada (PADILHA, 2012).

Com base no exposto, pode-se inferir que a ausência das três esferas de reconhecimento foi um fator essencial para a entrada de Sandro no mundo da criminalidade e que a busca por reconhecimento marcou sua trajetória de vida. Claro que esse foi um fator primordial, mas não o único. A questão político-econômica também deve ser considerada, ou seja, a marginalização econômica e a privação de um padrão de vida material adequado também contribuíram para a situação, mas iremos nos ater aos valores simbólicos, geradores de uma "injustiça cultural”, cujo remédio principal é o reconhecimento (FRASER, 2006).

\title{
3 A MÍDIA COMO ESPAÇO DE RECONHECIMENTO
}

\begin{abstract}
Esse menino com essa arma pode produzir em nós ou em outro qualquer um sentimento que é o sentimento do medo, um sentimento negativo, mas um sentimento através do qual ele recupera a visibilidade, reconquista a presença, reafirma a sua existência social, sua existência humana. É um processo aí de autoinstituição, uma estética da autoinvenção que se dá pela mediação da violência, de modo perverso, é um pacto fáustico que o menino troca o seu futuro, a sua vida, a sua alma, por assim dizer, por esse momento efêmero, fugaz de glória, a pequena glória de ser reconhecido, de ter algum valor, de poder prezar a sua autoestima. Esse é o momento crucial, é o momento matricial da nossa problemática toda, se nós compreendermos a profundidade, a complexidade desse momento, aí nós saberemos como agir (PADILHA, 2002, grifo nosso).
\end{abstract}

A visibilidade social, extremamente relacionada ao reconhecimento, foi "conquistada" por Sandro na situação pontual do assalto ao ônibus, em grande parte, devido à mídia e ao poder de reverberar, potencializar, publicizar um produto, um fato ou uma pessoa. "Estudos diversos têm apontado que a imprensa exerce, entre outras, as funções de dar visibilidade à coisa pública, a demandas do público e a setores da sociedade, servindo como uma espécie de fórum" (MAIA, 2004, p. 551).

No início, ele parecia não ter se dado conta da dimensão que o caso tomaria. Pedia, inclusive, para que tirassem as câmeras, afastassem os fotógrafos, não era claro para os policiais e para as pessoas que estavam naquele momento o que Sandro queria, nem o que seria capaz de fazer. "Ele dizia que não queria câmera, que não queria fotógrafo, ele gritava pros policiais: Tira aquele cara dali. Havia um fotógrafo bem em frente ao ônibus" (PADILHA, 2002). Porém, com a chegada de mais e mais repórteres, foi ganhando confiança, 
em função da certeza de que ninguém faria mal a ele em frente às câmeras. "Quem ia matá-lo ali na frente de todas as câmeras de televisão? Na cabeça dele, ninguém” (PADILHA, 2002).

Ciente disso e consciente do poder da mídia de potencializar aquela situação, Sandro criou deliberadamente um jogo, uma encenação na qual as vítimas eram obrigadas a fazer parte. "Ele pedia pra todo mundo gritar, berrar e mostrar desespero, enfim, tanto eu, quanto a Janaína, quanto a Geisa, todo mundo entendeu isso. Todo mundo colaborou gritando e chorando, além do desespero que a gente tinha mesmo" (PADILHA, 2002).

Ao notar a presença das câmeras de TV, "o próprio sequestrador estabelece estratégias de comunicação com o público, personifica o criminoso sádico e encena dramatizações de maus tratos às vítimas. Além disso, simulou a morte de outra refém e solicitou ao grupo que demonstrasse pânico" (MAIA, 2004, p. 565-566).

Parecia que com aquela atitude, Sandro soaria mais amedrontador, mais violento e ganharia com isso mais visibilidade, sobretudo em frente às câmeras. Por isso, ele criou um personagem, com as reféns agia de uma maneira e para a mídia agia de outra. "O grau de violência dele está associado diretamente às câmeras. Ele sim estava preocupado ali em aparecer, representar a peça dele" (PADILHA, 2002).

É como se Sandro soubesse realmente que a espetacularização da cena ia trazer maior repercussão ao caso e, de fato, isso ocorreu.

Tudo o que as pessoas têm que ver lá fora é o maior desespero possível para que ele conseguisse [...] o que ele tava querendo. Existia naturalmente um diálogo paralelo, o que tava acontecendo pras câmeras e pras pessoas lá de fora e o que tava acontecendo lá dentro [...], só que quem tinha o controle disso era ele, a qualquer momento ele podia trocar isso e mudar (PADILHA, 2002).

A representação que Sandro queria passar não condizia com os relatos das pessoas próximas a ele, que asseguravam que o jovem nunca matou, que não era capaz de atos violentos como aqueles, os quais estava afirmando que faria. "Ele não ia matar ninguém porque não era do caráter dele, senão ele já teria matado antes, na vida dele, como menino de rua, solto por esse mundo, sem nada, se fosse do temperamento dele" (PADILHA, 2002).

No entanto, a todo o momento, Sandro gritava que ia matar as reféns e, "por trás das câmeras", dizia que não ia fazer mal a ninguém, exigia, apenas, que elas colaborassem com ele. 
Eu não vou atirar para matá-la, mas eu vou atirar e eu quero que todo o mundo grite e foi até na hora que a Geisa abriu uma janela e deu pra ver todo o mundo gritando, inclusive eu estava gritando muito. Aí foi uma encenação, não deixou de ser uma encenação (PADILHA, 2002).

O caso ganhou destaque na mídia. "Existiam pessoas o tempo inteiro da imprensa, tentando chegar cada vez mais perto, e obter melhores informações, melhores imagens, esse tipo de coisa" (PADILHA, 2002). As pessoas em casa acompanhavam, ao vivo, o desenrolar da situação, criando um clima tenso e de expectativa para que terminasse com a morte de Sandro e a liberação das reféns com vida.

A coisa tomou uma dimensão porque ele sabia que eram muitas pessoas contra ele, todas as pessoas que estavam ali em volta do ônibus estavam, assim, preocupadas com a gente, né, com os reféns, e não com ele. Então, ele era o único contra todos (PADILHA, 2002).

Apesar de se sentir empoderado naquela situação e saber que em frente às câmeras provavelmente ninguém o mataria, em alguns momentos Sandro diz que não pode voltar para a prisão, porque iriam matá-lo e também sabia que a cada hora que passava ficava mais difícil fugir ileso. $\mathrm{O}$ medo e desespero são observados nesses momentos.

O prolongamento daquela situação também servia como espaço de significar alguma coisa para alguém, como espaço de mostrar que ele tinha poder, de mostrar que ele existia, enfim. E isso era uma coisa tão fundamental quanto resolver a situação e sair dali vivo. Nesse sentido, as câmeras de televisão importavam para ele (PADILHA, 2002).

Por outro lado, aumentava a pressão da sociedade para que a polícia agisse logo e resolvesse aquela circunstância. "Existia uma preocupação em resolver a situação e tirar o Sandro de lá, matar o Sandro ou então acabar com aquela situação” (PADILHA, 2002). No entanto, mais uma vez, a mídia influenciou a atitude dos agentes envolvidos, no caso, os policiais que, como dizem, fariam "o trabalho de limpeza" longe das câmeras.

À polícia cabe o trabalho sujo que a sociedade não quer ver, mas, que em algum lugar obscuro deseja que se realize - que se anulem os Sandros, que os Sandros desapareçam das nossas vistas, nós não queremos ver essa realidade, não podemos suportar essa realidade, então, a invisibilidade é afinal reconquistada pela produção policial da invisibilidade, da anulação que a morte gera (PADILHA, 2002). 
Porém, o final não foi o desejado e esperado pela grande maioria de espectadores que assistia "querendo ver um espetáculo e o espetáculo diz o seguinte: o final é a morte do bandido. Isso é comum na nossa sociedade" (PADILHA, 2002). Ao final, uma das reféns morreu por tiros dos policiais e de Sandro; e o sequestrador foi igualmente assassinado pelos policiais. "Eles mataram porque eles estão acostumados a matar e sabem que não vai dar em nada, porque quem é que vai defender um Sandro? Quem vai? Quem vai defender um Sandro? Ninguém" (PADILHA, 2002).

\section{MÍDIA, ESPETACULARIZAÇÃO DA VIOLÊNCIA E POLIFONIA}

A discussão sobre mídia, espetacularização e opinião pública está muito presente nos debates atuais, seja no mundo acadêmico, nas empresas que realizam pesquisas de audiência ou mesmo no cotidiano das pessoas.

É fato que a cobertura da criminalidade e da segurança pública tem avançado no Brasil, no entanto, a mídia, em alguns lugares, ainda opta por uma cobertura espetacularizada da violência. "Em primeiro lugar é preciso reconhecer que a violência em ato chama a atenção do público" (MAIA, 2004, p. 553). Supõe-se, com isso, que o trágico é uma forma de entretenimento e esse talvez seja um dos motivos pelos quais a violência é o instrumento usado com maior frequência pelas editorias policiais.

\footnotetext{
Através da transmissão ao vivo do sequestro, a violência em ato - o descontrole do sequestrador, o uso da força para manter os passageiros como reféns dentro do ônibus, a sequência de ameaças - pôde ser vista e ouvida por todos (MAIA, 2004, p. 553).
}

De acordo com Nery (2008), alguns estudiosos afirmam que a exploração da violência na mídia pelos meios de comunicação existe como forma de controle social. "A sensacionalização dos fatos sociais é uma condição inerente à produção da notícia em função das condições industriais da produção jornalística" (NERY, 2008, p. 28). Para a autora, a espetacularização da notícia se dá pela maneira com a qual os meios exploram o conteúdo da violência e está de acordo "com as formas de produção que propiciam a fragmentação, desmontagem, aceleração do processo de produção e consumo de informações que, no seu conjunto, favorecem a distorção, o falseamento da realidade, a exposição cindida dos fatos" (COSTA apud NERY, 2008, p. 28). 
Nesses casos, a qualidade da informação, na maioria das vezes, fica em segundo plano, prevalecendo a disputa pela audiência do público, visto como consumidor, em detrimento do papel de cidadão. Uma das formas de evitar apenas o registro dos fatos pela imprensa, principalmente quando o assunto em questão é a violência, seria a utilização do poder de persuasão da mídia na formação da opinião pública para desdobrar o factual e contribuir com uma formação sólida sobre o assunto.

Nesse contexto, a mídia é uma das maiores detentoras do poder de pré-estruturar a esfera pública, quando utiliza esse poder, por exemplo, para dar visibilidade a temas polêmicos a partir de pontos de vista diferentes e atores sociais diversificados. Dessa forma, “a esfera pública se constitui através do processo deliberativo, conforme caracterizado por Habermas, como um espaço de discussão, de elaboração e reflexão racionais, de busca de soluções para problemas comuns através de uma confrontação pública de argumentos" (MARQUES; MAIA, 2003, p. 75).

\begin{abstract}
Ali o Sandro nos despertou a todos nós em todas as salas de visita, ele impôs a sua visibilidade, ele era a personagem de uma outra narrativa, ele redefiniu de alguma maneira o relato social, o relato que dava a ele sempre a posição subalterna, de repente é convertido numa narrativa na qual ele é protagonista
\end{abstract} (PADILHA, 2002).

Nesse sentido, a mídia é capaz de organizar trocas argumentativas quando noticia um assunto polêmico formado por opiniões dissonantes. Por isso, é indiscutível sua importância para a colaboração de exercícios entre as diversas camadas sociais como, por exemplo, o de estimulo à prática da cidadania.

No caso de um processo deliberativo que envolva os Direitos Humanos, a mídia tem um papel fundamental no discurso por ter a possibilidade de contribuir com a manutenção de um debate mais bem fundamentado. Assim, a imprensa passa a ter um papel importante na discussão sobre assuntos públicos, "oferecendo as razões que motivam as ações, as recomendações ou os comandos, de tal modo a 'explicá-los' aos outros, por meio do discurso, num esforço de torná-los compartilhados e reconhecidos publicamente” (MAIA, 2002, p. $158)$.

Nesse processo, os jornalistas têm um papel fundamental como profissionais comprometidos com o interesse público e com um direito humano fundamental: o direito da população a ter uma informação de qualidade. E aqui a informação é compreendida não como mera mercadoria, que pode ser monopolizada por algumas poucas empresas ou restrita 
somente aos interesses das elites locais, mas como um bem social (GUIA DE DIREITOS HUMANOS, 2003, p. 19).

Padilha, no documentário Ônibus 174, utilizou-se do recurso da Polifonia (BARROS; FIORIN, 1999), característico do gênero, para justamente tentar abarcar as múltiplas vozes e visões diferentes sobre o mesmo fato. Indo de encontro às matérias publicadas no período do acontecimento do sequestro, o diretor procurou dar visibilidade e reconhecer a história por trás do sequestrador, remontando sua trajetória de vida por meio dos inúmeros depoimentos e arquivos selecionados.

\section{CONSIDERAÇÕES}

Com base na observação do documentário, conclui-se que a ausência das três esferas de reconhecimento - amor, direito e solidariedade - foram fatores essenciais que contribuíram para a entrada de Sandro no mundo da criminalidade, corroborando, portanto, com a Teoria de Axel Honneth, na qual a ausência de reconhecimento é um fator tão ou mais importante do que a situação econômica e a privação de bens materiais, quando estamos tratando sobre temas como: conflitos urbanos, violência e criminalidade.

$\mathrm{O}$ auge do reconhecimento, para Sandro, foi conquistado no momento do sequestro, situação na qual ele era o protagonista, narrador da própria história, detentor de todos os olhares. Era a oportunidade que poderia dizer e ser ouvido. Tinha o poder circunstancial de decisão, reconquistou a sua visibilidade social.

Consciente das potencialidades da mídia, Sandro utilizou estratégias para criar um espetáculo, inventou um jogo paralelo, no qual foram incluídas as reféns. Montou uma encenação para ser apresentada em frente às câmeras e por trás agia de outra maneira. Garantiu, com isso, a espetacularização do caso e o ápice de reconhecimento, que, apesar de ser negativo para os que estão em volta, era para ele um momento de glória, de reafirmação social.

José Padilha deliberadamente também devolveu ao Sandro, pós-morte, o reconhecimento que este tanto buscou ao longo da vida, quando optou pelo gênero documentário, no qual pôde utilizar a polifonia para recuperar elementos que foram omitidos (nas matérias da época), mas que, reconstruídos nos depoimentos colhidos, mostram que Sandro também foi a grande vítima do caso, vítima de um sistema, de uma trajetória perversa 
de vida que o levou às ruas, ao cometimento de crimes e que culminou com a morte prematura e cruel.

\section{REFERÊNCIAS}

BARROS, Diana Luz Pessoa; FIORIN, José Luiz. Dialogismo, polifonia, intertextualidade. São Paulo: Edusp, 1999.

FRASER, Nancy. Da redistribuição ao reconhecimento? Dilemas da justiça numa era pós-socialista. Cadernos de campo, São Paulo, n. 14/15, p. 231-239, 2006. Disponível em: < http://www.revistas.usp.br/cadernosdecampo/article/viewFile/50109/54229>. Acesso em: 05 jan 2015.

FUHRMANN, Nadia Lucia. O Primado do Reconhecimento sobre a Redistribuição: a origem dos conflitos sociais a partir da teoria de Axel Honneth. Sociologias [online], Porto Alegre, v.15, n.33, p.170-203, mai/ago.2013. Disponível em:

<http://seer.ufrgs.br/index.php/sociologias/article/view/42436/26831>. Acesso em: 15 jan 2015.

GUIA de Direitos Humanos: Fontes para jornalistas. São Paulo: Cortez, 2003.

HONNETH, Axel. Kampf um Anerhennung: Zur moralischen Grammatik sozialer Konflikte. Frankfurt am Main: Suhrkamp, 2003.

MAIA, Rousiley C. M. Media e deliberação pública: mediações possíveis (completo). Rio de Janeiro: Compós, 2002.

Visibilidade e accountability: o evento do ônibus 174. ENCONTRO ANUAL DA

COMPÓS, XIII, 2004b. Anais... São Bernardo do Campo, 2004. Disponível em: <http://www.sopcom.pt/actas/maia-rousiley-visibilidade-accountability.pdf $>$. Acesso em: 12 jan 2015.

MARQUES, Ângela C. S.; MAIA, Rousiley C. M. O apelo emocional e a mobilização para a deliberaçãa. Contemporânea, ano 1, n. 1, p. 71-104, 2003.

MENDONÇA, Ricardo Fabrino. Dimensão intersubjetiva da auto-realização: em defesa da teoria do reconhecimento. Revista Brasileira de Ciências Sociais, v.24, n.70, p.143-154, jun. 2009. Disponível em: < http://www.scielo.br/pdf/rbcsoc/v24n70/a09v2470.pdf>. Acesso em: 02 jan 2015.

NERY, Lena. Imagem violada: estereótipos e desrespeito aos direitos do adolescente em conflito com a lei nos jornais Diário do Pará e O Liberal. 2008. 78f. Monografia (Especialização Imagem e Sociedade) - Instituto de Letras e Comunicação, Universidade Federal do Pará, Belém, 2008.

NICHOLS, Bill. Introdução ao Documentário. Trad. Mônica Saddy Martins. Campinas, SP: Papirus, 2005.

PADILHA, J. (diretor). (2002). Ônibus 174 [DVD]. 133 min. Rio de Janeiro: Riofilme.

SAAVEDRA, Giovani A.; SOBOTTKA, Emil A. Introdução à teoria do reconhecimento de Axel Honneth. Civitas, Porto Alegre, v. 8, n. 1, p. 9-18, jan/abr. 2008. 
Especialista em Língua Portuguesa (UFPA) e Mestre em Comunicação pelo Programa de PósGraduação em Comunicação, Cultura e Amazônia (PPGCOM-UFPA) Doutora em Desenvolvimento Sustentável do Trópico Úmido pela Universidade Federal do Pará. Professora do Departamento de Comunicação Social da Universidade Federal do Rio Grande do Norte e da Pós-Graduação em Comunicação, Cultura e Amazônia da Universidade Federal do Pará (PPGCOM-UFPA)

\section{Corporativa (Esamaa) e Mestre em Comunicaçă} Monique Feio Igreja Programa de Pós-Graduação em Comunicação, Cultura e Amazônia (PPGCOM-UFPA).

Professora da Faculdade de Comunicação da Universidade Federal do Pará

Esta obra está licenciada sob uma Licença Creative Commons. 